\title{
The Role Of Reputation In Market Entry: Evidence From French Public Procurement
}

\author{
Maher Kachour, IDRAC Business School, France \\ Olivier Mamavi, ICD Business School, France \\ Haithem Nagati, ICD Business School, France
}

\begin{abstract}
This article studies the impact of reputation on market entry in public procurement. Based on the observation of a French firm with a strong reputation, we demonstrate a significant effect of the difference in public contracts won between date $t-1$ and date $t$. Our model provides empirical proof that selection of a supplier with a strong reputation does not hinder entry in public procurement nor does it prevent free competition. This result thus questions the justification for the European Union regulation that limits the use of information on past performance to select suppliers in public markets. The findings also suggest that reputation mechanisms can help reduce uncertainty during contract execution.
\end{abstract}

Keywords: Reputation; Market Entry; Public Procurement; Contract Awarding; Past Performance

\section{INTRODUCTION}

Qf everal studies show that reputation influences firm performance (Fombrun and Shanley, 1990; Landon and Smith, 1997; Roberts and Dowling, 2002; Stuebs and Sun, 2009). This performance also raises the problem of the role of reputation in market access. Specifically, does the strong reputation of a firm create a barrier to market entry for other firms?

To understand the impact of reputation, we concentrated on public markets. In 2011, public markets in Europe represented over $€ 2$ billion, or nearly $19 \%$ of GDP. In fact, the efficiency of public procurement has often been questioned. The supplier selection phase, particularly regarding contract awarding criteria, has been discussed extensively. Information asymmetry complicates the choice of supplier for a public buyer, and makes it difficult to foresee behaviour during contract execution.

It would be logical to think that a firm's reputation creates an advantage that may dissuade, hinder, decrease or delay access to a market for other firms. In economics, entry barriers play an important role in many subjects related to competition.

However, to reduce opportunistic behaviour by some suppliers, notably in complex contracts, public buyers may be tempted to use reputation as a selection criterion in awarding public contracts. Reputation, measured by past performance, allows more efficient coordination of trade (Hart and Moore, 1999), reduced transactions costs (Williamson, 1985; Yukins, 2008) and management of contractual incompleteness (Tirole, 1999).

The relation among reputation, competition and entry barriers has been an important topic in the debate on regulation of public procurement (European Commission, 2011).

Consequently, the selection criterion of past performance can be both an incentive measure to increase the quality of tenders and an entry barrier for new suppliers. Further, Spagnolo (2012) demonstrates that reputational mechanisms can be designed to stimulate rather than hinder new entry.

The objective of this study is therefore to determine the extent that a firm's reputation affects the awarding of public contracts. Specifically, we investigate whether mechanisms based on evaluation of past performance can improve governance of public contracting in Europe. 
To make an original contribution, we observe the awarding of French public contracts over a six-year period. We perform a longitudinal analysis of past performance of the firm with the strongest reputation by applying the firstorder Signed INteger-valued AutoRegressive model (SINAR). The estimates produced by the model demonstrate the weight of the impact of reputation in public procurement. The main contribution of this empirical study is that it shows that selection of a supplier in public markets based on reputation does not necessarily create an entry barrier for public contracts and does not impede free competition.

The remainder of the paper is organized as follows. First we present the theoretical foundations of reputation in public markets and the concept of entry barrier. Second, we describe the data used in the empirical study. Lastly, we propose, test and define the parameters of a model of reputation. The last section of the article provides a discussion and some recommendations.

\section{THEORETICAL BACKGROUND}

\subsection{Awarding Public Procurement Contracts}

In France, the Code des Marchés Publics (Public Procurement Contracts Code - PPCC, 2012), inspired by European directives (European Parliament, 2004), sets the legal framework for public procurement (Gelderman et al., 2006). Public procurement is defined as a contract concluded, in return for payment, between a public contractor and a private economic operator. The purpose of the contract is to satisfy needs in works, goods or services (PPCC, 2012).

For public powers, the quest for the lowest purchasing costs is a fundamental objective (Loader, 2010), and promoting competitive tendering among suppliers is a means long used to lower these costs, particularly through calls for tenders (Arlbjørn \& Freytag, 2012). In the French context, suppliers engage in a procedure of competitive tendering, after which the most economically advantageous bid is retained (PPCC, 2012). Competitive tendering procedures are part of a logic aimed at maximally reducing collusion between the public sector and private firms, and at avoiding favouring one candidate over another. To make the best choice, public buyers use the following criteria: quality, price, technical value, aesthetic and functional character, performance in environmental protection, performance in professional integration of persons excluded from the labour market, global usage costs, innovativeness, after-sale service and technical assistance, delivery date, delivery time and execution time (PPCC, 2012). However, purchasers can also ask suppliers to provide information that would let them assess their experience, or their technical, professional or financial capacity.

Unlike in the private sector, however, public procurement entails very formal contracts subject to major administrative constraints (Arlbjørn \& Freytag, 2012). Public buyers therefore face two main difficulties in contract management, regardless of the contract phase (selection, monitoring of execution, closing). First, the public buyer cannot directly observe the supplier's performance (information asymmetry). Second, it cannot foresee all the contingencies that will affect the contract during its execution (contractual incompleteness).

\subsection{Contractual Incompleteness}

As Saussier and Tirole (2015) maintain, contract management is characterised by numerous risks: risk of collusion when markets are concentrated, risk of "winner's curse" when the best tender comes from the most optimistic partner rather than the most efficient one, risk of receiving overly aggressive offers from suppliers simply aiming to be selected, which intend to renegotiate the contract later; risk of moral hazard, where a firm that wins a contract with the public authorities may later, when the contract is awarded, prove to be inefficient or even inattentive at managing it; risk of hold up if the supplier confiscates the surplus of the transaction; risk of corruption, etc.

Risksharing in public contracts is therefore essential because it determines both the level of accountability of the firm and its profit. The firm naturally has better knowledge of the technology available, procurement costs, and demand for products and services included in the public contract. Further, the costs and demand are not linked to its decisions in human resources management, choice of production capacities, research and development, service quality, risk management, etc. 
Consequently, the public buyer and its supplier cannot foresee, and hence stipulate what must happen in all possible cases. The contracting parties cannot write a complete contract in which all characteristics are described in sufficient detail for a court to order their application. This information asymmetry is inherent in public procurement.

As a result of information asymmetry, the public buyer will seek other means to achieve effective coordination of commerce (Hart and Moore, 1999). Several solutions are possible. First, contracts are generally concluded following a competitive process. Competitive tendering procedures are a means long used to lower purchasing costs because it obliges suppliers to disclose information about their cost price and margin (Loader, 2010; Arlbjørn \& Freytag, 2012). Incentive mechanisms may also be applied, such as comparing firms' performance with that of similar firms operating in different markets, or putting the offer up for auction to identify the most efficient firm. Procedures that create competition are also part of a logic aimed at maximally reducing collusion between the public buyer private firms, to avoid favouring one candidate over another, and to guarantee the integrity of the procurement process (Vagstad, 1995; Drabkin and al., 2005).

\subsection{Role of Reputation}

To resolve information asymmetry between the public buyer and suppliers, another alternative is to rely on trust (based on expectations of future behaviour) or on reputation (based on past behaviour). Asymmetry is due to the fact that public procurement contracts are incomplete because they do not allow public buyers to address the unforeseeability of tasks to perform. Contractual incompleteness is explained by the unverifiability of characteristics by a third party and by the indescribability of future contingencies (Maskin and Tirole, 1999; Tirole, 1999).

This is why, in contracts with great uncertainty, reputation becomes a signal of the good quality of a firm's products or services (Shapiro, 1983). Podolny and Phillips (1996) maintain that "reputation is determined by the value (quality) of the actor's previous efforts." A strong reputation provides several advantages. Notably, it can reduce transaction costs because the partners are less concerned with contractual risks (Jensen and Meckling, 1976; Roberts and Dowling, 2002). It also improves the perception and impact of the commercial offer (Dowling, 2001). It encourages suppliers to respect their commitments and thus deserve the buyer's trust (Milgrom and Roberts, 1988). In addition, it encourages ethical behaviour (Sacconi, 2007).

As Fombrun (1996) contends, reputation is "a perceptual representation of a company's past actions and future prospects." This view is confirmed by empirical studies that demonstrate a positive relationship between firm reputation and performance (Fombrun, and Shanley, 1990; Landon and Smith, 1997; Roberts and Dowling, 2002; Stuebs and Sun, 2009).

However, Spagnolo (2012) notes that the use of reputation as a supplier selection criterion is widespread in the private sector, unlike in the public sector. In the public sector, the need to avoid favouritism and corruption have led legislators to encourage contract awarding procedures that are open and transparent, and that treat all suppliers equally.

Yet some experiences in the public sector affirm the role of reputation in candidate selection. For example, Mamavi et al. (2015) prove that the supplier selection process may be influenced by the supplier's past performance and by the sector of activity of the transaction. Decarolis et al. (2014) present a real experiment that provides empirical evidence of the effect of announcing the use of past performance information when awarding a public procurement contract. Lamothe and Lamothe (2012) show how local governments tend to place more confidence in their vendors' faithfulness and honesty when their contracting partners have strong community ties and perform their tasks well. Van Slyke (2007) contends that public buyers use reputation as a sanction or reward mechanism to control supplier behaviour.

These findings lead us to formulate our first research hypothesis:

H1: The strength of a firm's reputation has a significant effect on its ability to win public contracts. 


\subsection{Entry Barriers}

Consensus has not yet emerged in the academic literature regarding the definition of entry barrier. Nonetheless, scholars agree that this term refers to an obstacle that hinders a firm's access to a market. Shepherd $(1979)$ specifies two categories of entry barriers. Exogenous barriers are linked to cost advantages (product quality, brand image, distribution circuit, research and development, etc.), whereas endogenous barriers are related to competitive behaviour of incumbent firms in accordance with their market strategies (competitors, price, advertising, etc.). Barriers affect firm strategy relative to two components: the commercial offer proposed and access to the market (Pehrsson, 2009).

For public markets, the American Senate conducted a study that shows that past performance or the need for prior experience may be an obstacle to market entry for small or new firms and may hinder the ability of such firms to win calls for tenders (GAO, 2011). This conclusion has been confirmed by other authors. For example, Butler et al. (2013) argue that inappropriate reputation mechanisms may create an entry barrier to the market by limiting the number of candidates. In their study of public e-markets, Spagnolo and Dini (2005) show that the existence of a reputation mechanism favours incumbents over newcomers. The lack of information on newcomers reduces the possibility of interaction, discourages participation and implies fewer commercial opportunities. This generates an entry barrier that encourages newcomers to formulate abnormally low bids to make up for their lack of reputation. Mailath and Samuelson (2001) assert that a strong reputation obliges all newcomers, whose reputation is weak, to spend more to improve the perceived quality of their tender.

This leads us to formulate our second research hypothesis:

H2: A firm's strong reputation is an entry barrier to public markets for other firms.

\section{DESCRIPTION OF DATA}

The problem with measuring firm reputation is that reputation often stems from stakeholders' perceptions or evaluations. As a result, this type of measure is very volatile, and is highly contingent on stakeholders, relations and interests (Koronis and Ponis, 2012). This is why we have retained past performance as the main indicator of firm reputation (Spagnolo, 2012).

To assess the impact of suppliers' performance history on their current win performance, we have chosen to study the case of France. Specifically, we collected all transactions of "1298" suppliers between 2006-01-02 and 201106-09, as stated in French Official Journals (www.boamp.fr). Note that throughout this period there were only 450 days where the public sector has issued calls for tenders. Further, we selected this supplier because it obtained the most tenders during this period. Namely, "1298" won 1910 public procurement contracts. Let $\left(X_{t}\right)$ denote the time series of daily number of contracts won by "1298." Thus, the recorded data above are considered as observations of this process. Associated descriptive statistics are given in the following table:

Table 1. Summary of observed daily number of contracts won by "1298"

\begin{tabular}{c|c|c|c|c}
\hline Minimum & Median & Mean & Std deviation & Maximum \\
\hline 0 & 0 & 4.258 & 18.31876 & 138 \\
\hline
\end{tabular}

The observations of the process are displayed in Figure 1. Based on the observed data and by using the KPSS test (for details, see Kwiatkowski et al., 1992), one can deduce that the time series is not stationary. In such case, we need to use the differencing operator to achieve stationarity. Thus, let us consider $\left(Y_{t}\right)$ time series, where $Y_{t}=X_{t}$ $X_{t-1}$. Explicitly, $Y_{t}$ denotes the difference between the number of contracts won by " 1298 " at time/day $t$ and that of $\mathrm{t}-1$.

\footnotetext{
${ }^{1}$ Supplier ID code. 
Figure 1. Plot of observed daily number of contracts won by "1298" from 2006-01-02 to 2011-06-09

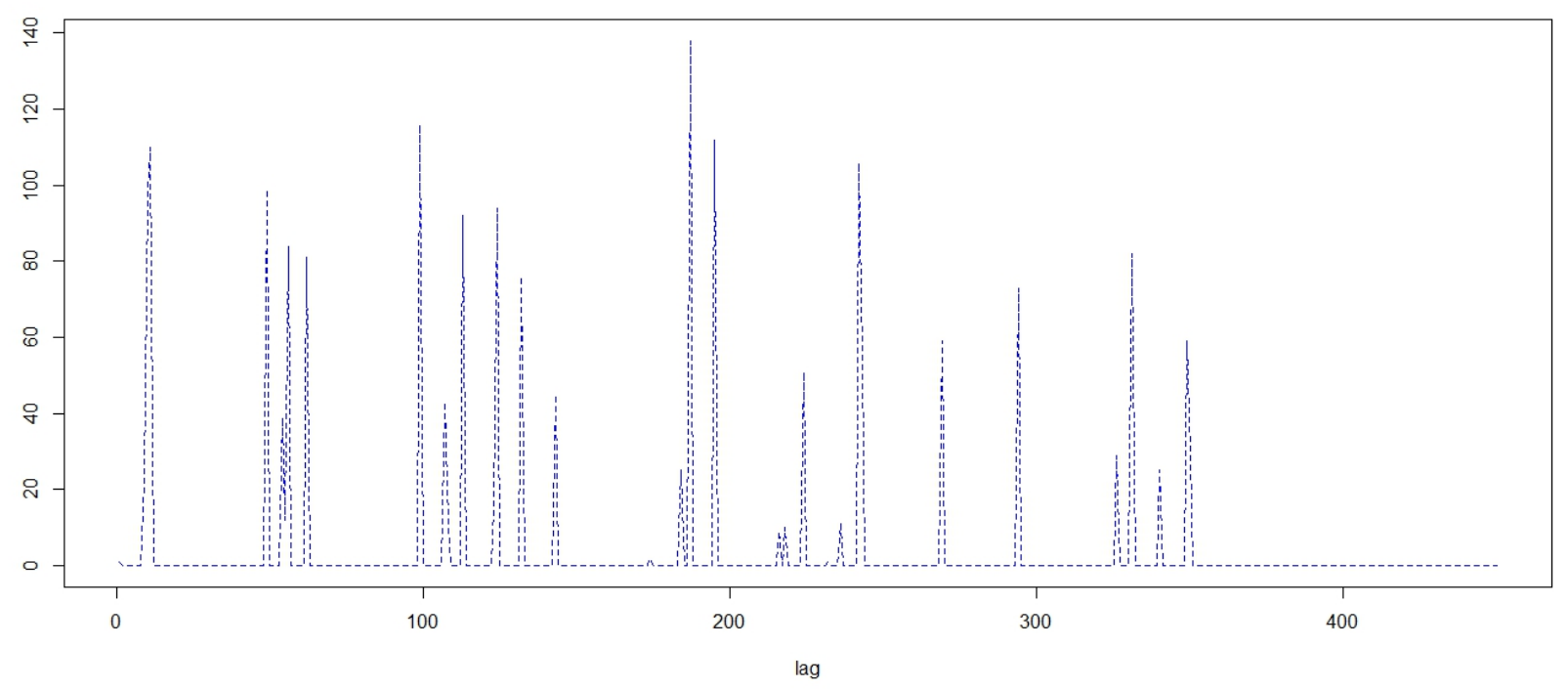

Based on the original data, Figure 2 presents the observations of for the period between 2006-01-09 and 2011-06-09. Of course, we now have 449 observations instead of the 450 originally collected. Note that here the KPSS test shows that no evidence that the observed data of this new times series are not stationary.

Figure 2. Plot of observed data of the process $\left(Y_{t}\right)$ from 2006-01-09 to 2011-06-09

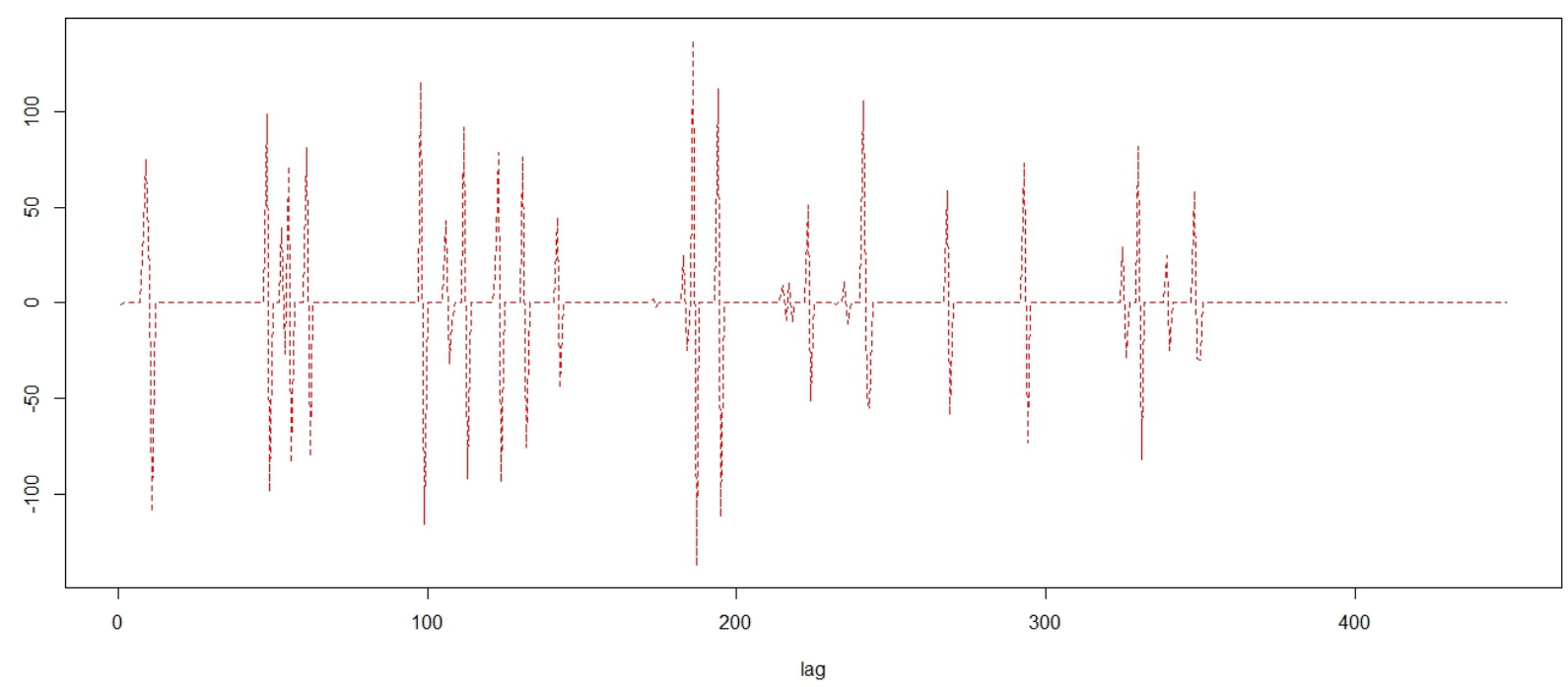

Next, to check the quality of the chosen model to fit the data, we took the 400 initial observations of the time series as a learning set (i.e., to estimate the parameters of the chosen model) and use the 49 latest observations of the time series as a test set for forecasting. 


\section{MODEL SPECIFICATION AND RESULTS}

Recall that, by definition $\left(Y_{t}\right)$ is an integer-valued time series. Associated descriptive statistics are given in the following table:

Table 2. Summary of observed data of $\left(Y_{t}\right)$

\begin{tabular}{c|c|c|c|c}
\hline Minimum & Median & Mean & St-deviation & Maximum \\
\hline-140 & 0 & -0.0375 & 21.89611 & 145 \\
\hline
\end{tabular}

Further, the sample Auto-Correlation-Function (ACF) and sample Partial-Auto-Correlation-Function (PACF) have values significantly different from zero at lag 1 (see Figure 3).

Figure 3. From left to right, plot of sample ACF and sample PACF of $\left(Y_{t}\right)$, based on the first 400 observations only
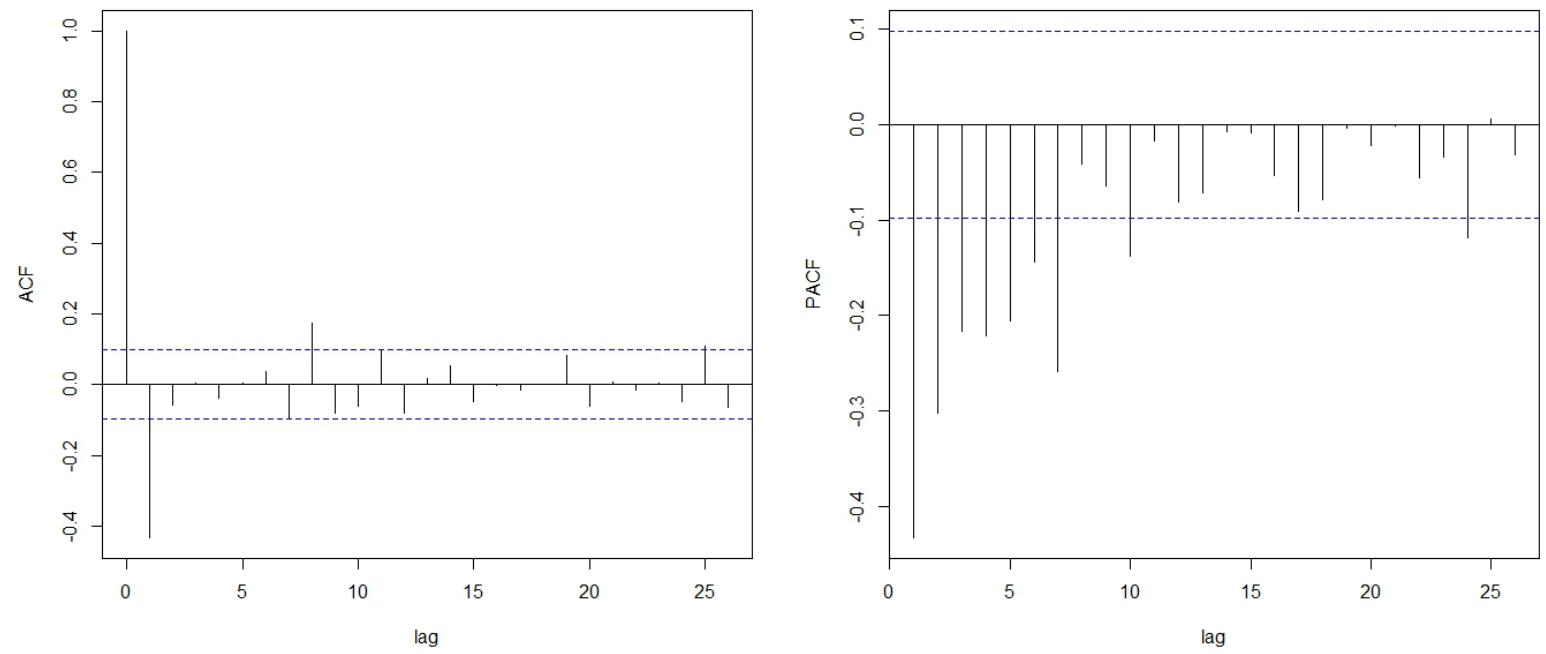

Thus, to analyse this time series, we suggest the first-order Signed Integer-valued AutoRegressive SINAR (1) process:

$$
Y_{t}=\alpha^{\circ} Y_{t-1}+\varepsilon_{t}
$$

with

$$
\begin{aligned}
& \alpha^{\circ} Y_{t-1}=\operatorname{sign}\left(Y_{t-1}\right) \sum_{i=1}^{Y_{t-1}} Z_{i} \\
& p=E\left(\varepsilon_{t}\right)
\end{aligned}
$$

where, for an integer $x, \operatorname{sign}(x)=1$ if $x>0$ and -1 if $x<0,\left(Z_{i}\right)$ a sequence of i.i.d. integer-valued random variables (called counting series) independent of $Y_{t-1}, \alpha=E\left(Z_{i}\right)$, and $\left(\varepsilon_{t}\right)$ a sequence of i.i.d. integer-valued random variables, independent of the counting series $\left(Z_{i}\right)$, with $p=E\left(\varepsilon_{t}\right)$ 
Using the conditional least squares estimator, one can obtain:

$$
\begin{gathered}
\widehat{\alpha}=-0.4318 \\
(0.0451)
\end{gathered} \text { and } \hat{\rho}=-0.0016
$$

as an estimation of unknown parameters $\alpha$ and $\rho$ respectively (standard errors, reported in brackets below each estimate). Furthermore, one can deduce, using a t-test, that $\alpha$ is significantly different from zero at the $95 \%$ significance level. Therefore, one can say that the value of $Y_{t}$ (the difference between the number of contracts won by "1298" at time/day t and that of t-1) can be explained partly due to $Y_{t-1}$ (the difference between the number of contracts won by " 1298 " at time/day $t-1$ and that of $t-2$ ). In other words, the historical performances of supplier "1298" could explain its actual win performance. On the other hand, the one-step ahead least squares forecast $\tilde{Y}_{t+1}$ of $Y_{t-1}$ equals:

$$
\tilde{Y}_{t-1}=\hat{\alpha} Y_{t}+\hat{\rho}
$$

In general $\tilde{Y}_{t+1}$ is real-valued. A mapping into the discrete support of the series is obtained by rounding to the nearest integer. Note that all values of the test set for forecasting (last 49 observations) are equal to zero. Using the one-step forecast defined in the above equation (and after the rounding map), one can also see that all forecasting values for the test set are null. This result can be explained by the fact that the observations of $\left(Y_{t}\right)$ remain invariant (equal to zero) over a long time interval especially at the end (see Figure 2), and the estimate value of $\rho$ is sufficiently small for varying forecasts.

Note that the SINAR (1) process used to fit our data was introduced by Kachour and Truquet (2011), who show that SINAR (1) has the same properties as that of the standard real-valued first-order AutoRegressive AR (1) process (for details on the real-valued AR (1) process, refer to Duflo (1997)). Further, unlike most integer-valued models in the literature, the SINAR process can deal with integer-valued time series with negative observations and negative autocorrelations. Therefore, this process can be used to analyse integer-valued times series that have the same empirical characteristics as those of an AR process. The major indicator of these attributes is often found through an empirical autocorrelation structure. For instance, Kachour and Truquet (2011) have used the SINAR process to analyse Fürth data (counts of pedestrians on a city block observed every 5 seconds) and the annual Swedish population rates for the century of 1750 to1849.

$$
\begin{array}{cc}
\widehat{\alpha}=-0.4318 & \hat{\rho}=-0.0016 \\
(0.0451) & (0.8200)
\end{array}
$$

\section{DISCUSSION AND IMPLICATIONS}

Our findings validate the first hypothesis: the strength of a firm's reputation has a significant effect on the firm's ability to win public contracts. The estimation of the parameter of our model is -0.4318 , which indicates that the possibility of the firm " 1298 "'s winning a contract depends significantly on its having won the previous contract.

In contrast, the findings lead us to reject the second hypothesis: the strength of a firm's reputation is a barrier to public market entry. Because the estimate of the parameter of our model is negative, there is a significant probability of $43 \%$ that firm " 1298 " will not win the next contract on which it tenders if it has won the previous contract.

To encourage the use of reputation as criteria in awarding European public contracts process, these results therefore lead us to formulate the following two recommendations.

\subsection{Managerial Implications}

Given that our second hypothesis is refuted, we can conclude that the strength of a firm's reputation does not impede entry in procurement. Consequently, this result supports the use of reputation mechanisms based on past performance, as in the case in the USA or South Korea, for example. This system can encourage firms to honour 
their contractual commitments in that it would make information on firms' reputation more easily accessible to contracting entities.

Bannerjee and Duflo (2000) demonstrated the effectiveness of a ratings-based reputation mechanism in the private sector. In the United States, the Internet Federal Awardee Performance and Integrity Information System (FAPIIS) aggregates multiple sources of information (including Past Performance Information Retrieval, PPIRS, and the Contractor Performance System, CPS) and helps federal services in charge of procurement to select suppliers by providing pertinent and up-to-date information on firms' history for the last five years. In Europe, Spagnolo (2012) conducted an empirical study of a large Italian public services firm that introduced an experimental rating system for its subcontractors and used a reputation criterion in its selection procedures. The study finds that this approach increased quality, and that simple rules for rating reputation can avoid favouritism and the creation of entry barriers for newcomers that lack past experience with the public contractor.

Our results extend the works of Butler et al. (2013), who conducted a laboratory experiment in which they modelled the relationship between reputation and entry in procurement. They implemented a repeated procurement game with reputational incentives for quality and the possibility of entry. They design reputation as an incentive system to limit moral hazard in the quality dimension as well as on the effect of reputation on selection through entry. Their results suggest that while some reputational mechanisms may indeed reduce the frequency of entry besides increasing quality so that the concern is indeed warranted, well-designed reputational mechanisms with positive entry reputation need not hinder entry and may actually stimulate it.

This reputation mechanism based on past performance is similar to the measures taken in the USA. Since 2005, when public contracts are awarded, the Federal Acquisition Regulation (FAR) requires agencies to consider firms' performance records to help ensure that taxpayer dollars go to capable contractors. As in the private sector, the FAR also gives public contracting authorities considerable power to decide how they will consider firms' past experience and the quality of work executed (GAO, 2011).

\subsection{Legal Implications}

The results of this study underline the value of improving the legislative framework governing the inclusion of reputation in contract awarding criteria. Currently, regulation on public procurement (European Commission, 2011) limits the use of information on past performance in qualitative selection criteria. These directives stipulate that concerning technical and professional capacities: "contracting authorities may require, in particular, that economic operators have a sufficient level of experience demonstrated by suitable references from contracts performed in the past" (article 58, paragraph 4). Nonetheless, article 57 of the directive (European Parliament, 2014) foresees that firms may be excluded "where the economic operator has shown significant or persistent deficiencies in the performance of a substantive requirement under a prior public contract, a prior contract with a contracting entity or a prior concession contract which led to early termination of that prior contract, damages or other comparable sanctions."

These regulatory provisions may lead firms to honour their contractual commitments and thus avoid opportunistic behaviours intended to win a contract by underestimating costs. However, we recommend the reinforcement of negotiated procedures like "competitive procedure with negotiation," and "competitive dialogue" (European Parliament, 2014). Flexibility in the use of a negotiated procedure would limit the use of calls for tenders to procurement of products, services or standardised work, as opposed to specific projects. As Chong et al. (2014) demonstrate, the selection of contracting mode is dictated less by conditions of economic efficiency then by the fear of being accused of favouritism. The use of negotiated procedures that can consider suppliers' reputation is more effective than a call for tenders mainly in complex markets, in which proposals must include innovative conception or solutions (Estache et al., 2009). 


\section{CONCLUSION}

This paper examined the impact of reputation on firms' access to public procurement. Regarding supplier selection, our results show that reputation is a criterion used by public buyers, but it is not an obstacle that hinders, decreases or delays the awarding of a contract to another firm. Note that this study has one main limitation. In our model, information on contract execution was not considered in the estimation of the firm's reputation. This lack of information is mainly due to content of the European directive for public procurement (European Parliament, 2014), which covers the awarding phase but virtually overlooks contract management. In fact, a supplier's performance may be very different from what was promised before it was selected, and what is done once it obtains the contract. One of the main challenges related to increasing the efficiency of public procurement within the European Union would therefore be to encourage and centralise information on both contract awarding and execution.

\section{AUTHOR BIOGRAPHY}

Maher Kachour is a research professor at IDRAC Research. He holds a $\mathrm{PhD}$ in the field of applied mathematics with a specialty in statistics, from IRMAR, University of Rennes 1, France. Maher is a project leader for online Human Resource Management (software developer) and an elected member of the steering group Rethinking Business Models. His research interests include business models and applications, integer-valued time series, and statistical distributions. Maher teaches Statistical Analysis, Research Methodology and Introduction to Business Models. E-mail: maher.kachour@idraclyon.com

Olivier Mamavi is an associate professor of competitive intelligence at ICD Business School, Paris (France). He earned his Ph.D. in management from University of Poitiers (France). His main research goals are to understand the behavior of public purchasers, explain strategies to influence public decision and predict contract awards in public procurement. E-mail: omamavi@groupe-igs.fr (Corresponding author)

Haithem Nagati is a professor at the Institut International du Commerce et du Développment Paris, France. He received his Ph.D. in management from the University Pierre Mendès France Grenoble. His interests include customer-supplier relationships, knowledge management and performance management. His work has been published in Supply Chain Forum, International Journal of Operations and Production Management, Industrial Marketing Management and Production Planning and Control. E-mail: hnagati@groupe-igs.fr

\section{REFERENCES}

Arlbjørn, J., Freytag, P., \& de Haas, H. (2011). Service supply chain management: A survey of lean application in the municipal sector. International Journal of Physical Distribution \& Logistics Management, 41(3), 277-295.

Bannerjee, A., and Duflo, E. (2000), Reputation Effects and the Limits of Contracting: A Study of the Indian Software Industry. Quarterly Journal of Economics, 115(3), 989-1017.

Brammer, S. and Walker, H. (2011), Sustainable procurement in the public sector: an international comparative study, International Journal of Operations \& Production Management, 31(4), 452-476.

Butler, J. V., Carbone, E., Conzo, P., \& Spagnolo, G. (2013). Reputation and Entry in Procurement. CEPR Discussion Paper n ${ }^{\circ}$ 9651.

Chong, E., Staropoli, C. and Yvrande-Billon, A. (2014). "Auctions versus negotiations in public procurement: Looking for new empirical evidence”, Manufacturing Markets, E. Brousseau et J.-M. Glachant (Eds.): 120-142. UK: Cambridge University Press.

Decarolis, F., Pacini, R. and Spagnolo, G. (2014) The Role of Reputation when Awarding Contracts: Empirical Evidence from a Vendor Rating System. Working paper. (Chaire EPPP - IAE Paris)

Dowling, GR. (2001). Creating Corporate Reputations. Oxford University Press: Oxford.

Drabkin, D., Lloyd, R., \& Thai, K. (2005). Bid protests in the U.S. Federal government: An empirical analysis. In A. Ancarani \& M. Raffa (Eds.), Sourcing decision management. Napoli: Edizioni Scientifiche Italiane, 161-181.

Duflo, M. (1997). Random Iterative Models. Berlin: Springer-Verlag.

Estache, A., Guasch, J.L., Iimi, A. and Trujillon, L. (2009), Multidimensionality and renegotiation: evidence from transport sector public-private partnership transactions in Latin America, Review of Industrial Organization, 35 (1-2), 41-71.

European Parliament, (2004), Directive 2004/18/EU of the European Parliament and the Council of 31 March 2004. Official Journal of the European Union, available at http://eur-lex.europa.eu/ (access April 2015) 
European Commission (2011), Green Paper on the modernisation of EU public procurement policy - Towards a more efficient European Procurement Market, available at: http://ec.europa.eu/green-papers/index_en.htm\#2011 (accessed April 2015)

Fombrun, C. (1996). Reputation: Realizing Value from the Corporate Image. Boston: Harvard Business School Press.

GAO, (2011), Prior Experience and Past Performance as Evaluation Criteria in the Award of Federal Construction Contracts, US Government Accountability Office, available at http:/gao.gov/products/GAO-12-102R (accessed April 2015)/

Fombrun, C. and Shanley, M. (1990). What's in a name? Reputation building and corporate strategy. Academy of Management Journal, 33, 233-258.

Gelderman, C., Ghijsen, P., \& Brugman, M. (2006). Public procurement and EU tendering directives-Explaining noncompliance. International Journal of Public Sector Management, 19(7), 702-714.

Hart, O. and Moore, J. (1999), Foundations of incomplete contracts, Review of Economic Studies, 66(1), 115-138.

Jensen, Michael C., and William H. Meckling. (1976). Theory of the firm: Managerial behavior, agency costs and ownership. Journal of Financial Economics 3(4), 305-360.

Kachour, M. and Truquet, L. (2011). A p-order signed integer-valued autoregressive. Journal of Time Series Analysis, 32(3), 223-236.

Koronis, E., and Ponis, S. T. (2012). Introducing corporate reputation continuity to support organizational resilience against crises. Journal of Applied Business Research, 28(2), 283-290.

Kwiatkowski D. Phillips, P. C. B., Schmidt, P. and Shin, Y. (1992). Testing the Null Hypothesis of Stationarity against the Alternative of a Unit Root. Journal of Econometrics 54(1), 159-178.

Lamothe, M. and Lamothe, S. (2012). To Trust or Not to Trust? What Matters in Local Government-Vendor Relationships? Journal of Public Administration Research and Theory, 22(4), 867-892.

Landon, S., and Smith, C. E. (1997). The use of quality and reputation indicators by consumers: the case of Bordeaux wine. Journal of Consumer Policy, 20, 289-323.

Loader, K. (2010). Is local authority procurement 'lean'? An exploration to determine if 'lean' can provide a useful explanation of practice. Journal of Purchasing \& Supply Management, 16(1), 41-50.

Mailath, G. J., \& Samuelson, L. (2001). Who wants a good reputation? The Review of Economic Studies, 68(2), $415-441$.

Mamavi, O., Nagati, H., Pache, G., and Wehrle, F. T. (2015). How does performance history impact supplier selection in public sector? Industrial Management \& Data Systems, 115(1), 107-128.

Maskin, E. and Tirole, J. (1999), Unforeseen contingencies and incomplete contracts, Review of Economic Studies, 66(1), 83114.

Milgrom, P. and Roberts, J. (1988). Theories of the firm: Past, present, and future. The Canadian

Journal of Economics 21, 444-458.

Pehrsson, A. (2009). Barriers to entry and market strategy: a literature review and a proposed model. European Business Review, 21(1), 64-77.

Podolny, J.M. and Phillips, D.J. (1996). The dynamics of organizational status. Industrial and Corporate Change 5, 453-471

PPCC (2012), Public Procurement Contracts Code, Paris, available at: www.legifrance.gouv.fr/ (accessed March 2014).

Roberts, P. W. and Dowling, G. R. (2002). Corporate reputation and sustained superior financial performance. Strategic management journal, 23(12), 1077-1093.

Sacconi, Lorenzo. (2007). A social contract account for CSR as an extended model of corporate governance(II): Compliance, reputation, and reciprocity. Journal of Business Ethics 75:77-96.

Saussier, S. and Tirole, J. (2015), Strengthening the Efficiency of Public Procurement. Les notes du conseil d'analyse économique. $\mathrm{N}^{\circ} 22$ available at: www.cae-eco.fr/IMG/pdf/cae-note022-env2.pdf (accessed September 2015).

Shapiro, C. (1983). Premiums for high quality products as returns to reputations. Quarterly Journal of Economics 98, 659-679.

Shepherd, W. (1979), The Economics of Industrial Organization, Prentice-Hall, Englewood Cliffs, NJ.

Spagnolo, G., \& Dini, F. (2005). Reputation mechanisms and electronic markets: economic issues and proposals for public procurement in Araujo and al., (eds), Challenges in public procurement: an international perspective. Boca Raton, FL: PRAcademic Press.

Spagnolo, G., (2012), Reputation, Competition and Entry in Procurement, International Journal of Industrial Organization, 30(3), 291-296.

Stuebs, M., and Sun, L. (2009). Corporate reputation and technical efficiency: Evidence from the chemical and business services industries. Journal of Applied Business Research, 25(5), 21-30.

Tirole, J. (1999). Incomplete contracts: Where do we stand? Econometrica, 67(4), 741-781.

Vagstad, S. (1995). Promoting fair competition in public procurement. Journal of Public Economics, 58(2), 283-307.

Van Slyke, David M. (2003). The mythology of privatization in contracting for social services. Public Administration Review, $63,296-315$.

Yukins, C. (2008). Editor's note: a response to Omer Dekel's "Legal Theory of Competitive Bidding". Public Contract Law Journal, 37(2), 269-269.

Williamson, O.E. (1985). The Economic Institutions of Capitalism. Free Press, New York. 